\title{
UPAYA PENINGKATAN PENGETAHUAN REMAJA PUTRI TENTANG MENARCHE DI SDN 1 SINDANGSARI KABUPATEN PANGANDARAN
}

\author{
Wita Listiani*1, Siti Saadah Mardiah ${ }^{1}$, Dita Eka Mardiani ${ }^{1}$ \\ 1 Jurusan Kebidanan Poltekkes Kemenkes Tasikmalaya, Indonesia \\ *e-mail: witalistiani26@gmail.com
}

\begin{abstract}
World data of $76.3 \%$ of the world's adolescent population states that the population of young women mostly experiences stress during menarche. Other data shows as many as 54\% of young women get anxiety when menarche cannot do activities as usual with their peers. The average age of menarche in Indonesia is 13 years, with the incidence earlier at the age of less than 9 years or later until the age of 17 years. Menarche that is too early or late, can result in the mental state of these adolescents. Teens who will experience menarche need good mental readiness. The purpose of this community service is to increase teenage girl's knowledge about menarche. The target of this activity is teenage girl grade IV-VI who have not experienced menarche. The method used is health education. To identify the knowledge of young women about menarche before and after health education, pre-test and post-test were carried out. The results showed that most of them had sufficient knowledge (56.7\%) prior to health education. After the implementation of health education, most of them had good knowledge (53.3\%). It can be seen the average value before health education (56.8\%) and after health education (78.1\%). This shows an increase of $21.3 \%$.
\end{abstract}

Keywords: teenage girls knowledge, health education, menarche

\begin{abstract}
ABSTRAK
Data dunia sebesar 76,3\% dari penduduk remaja didunia menyatakan bahwa populasi remaja putri sebagian besar mengalami stress saat menarche Data lain menunjukan sebanyak $54 \%$ remaja putri mengalami rasa cemas saat menarche tidak bisa melakukan aktivitas seperti biasanya dengan teman sebaya. Rata-rata usia menarche di Indonesia adalah 13 tahun, dengan kejadian lebih awal pada usia kurang dari 9 tahun atau lebih lambat sampai usia 17 tahun.. Menarche yang terlalu dini atau terlambat, bisa berakibat pada keadaan psikis remaja tersebut. Remaja yang akan mengalami menarche membutuhkan kesiapan mental yang baik. Tujuan dari kegiatan ini adalah untuk meningkatkan pengetahuan remaja tentang menarche. Sasaran kegiatan ini adalah remaja puteri kelas IV-VI yang belum mengalami menarche. Metode yang digunakan adalah pendidikan kesehatan. Untuk mengidentifikasi pengetahuan remaja puteri tentang menarche sebelum dan sesudah pendidikan kesehatan dilakukan pre test dan posttest. Hasil menunjukkan sebagian besar mempunyai pengetahuan cukup $(56,7 \%)$ sebelum dilakukan pendidikan kesehatan. Sesudah dilaksanakan pendidikan kesehatan sebagian besar mempunyai pengetahuan baik (53,3 $\%)$. Dapat di ketahui rata-rata nilai sebelum dilakukan pendidikan kesehatan $(56,8 \%)$ dan sesudah dilakukan pendidikan kesehatan (78,1\%). Ini menunjukkan terjadi kenaikan sebesar 21,3\% .
\end{abstract}

Kata Kunci : Pendidikan Kesehatan, Pengetahuan Remaja, Menarche

76 | Edukasi Masyarakat Sehat Sejahtera (EMaSS) : Jurnal Pengabdian kepada Masyarakat Volume 2 No.1 Tahun 2020 


\section{PENDAHULUAN}

Menarche adalah menstruasi pertama yang bisa terjadi pada wanita, biasanya terjadi usia 10-16 tahun atau pada awal remaja (Proverawati, 2009). Menstruasi merupakan proses pelepasan dinding rahim (endometrium) yang di sertai dengan perdarahan dan terjadi secara berulang setiap bulan kecuali pada saat hamil maka seorang wanita tidak akan mengalami menstruasi (Haryono, 2016). Banyak remaja memandang bahwa menarche adalah suatu hal yang menakutkan karena akan menimbulkan ketidaknyamanan saat beraktivitas, pusing, sakit pada punggung dan anggota tubuh lainnya dan juga menyebabkan Pre Menstruasi Syndrome (PMS) (Hastuti, 2014).

Remaja putri bingung saat mengalami menstruasi pertama atau menarche karena mereka tidak tahu bagaimana mereka harus menyesuaikan diri terhadap aktifitas maupun rutinitas dengan datangnya menstruasi. Remaja tidak tahu bagaimana cara agar darah tidak merembes, remaja malu untuk membeli pembalut (Haryono, 2016). Salah satu faktor dari seseorang mempunyai presepsi atau sikap kurang baik adalah tingkat pengetahuan yang dimiliki seseorang. Pengetahuan dapat mempengaruhi sikap dan mempengaruhi tingkat kesiapan pada seseorang dalam menghadapi hal apapun adanya ketidaktahuan tersebut akan menimbulkan tekanan pada seseorang sehingga dapat menyebabkan stress. Disamping itu hal tersebut akan menimbulkan rasa positif maupun negative tentang menstruasi. Maka pengetahuan tentang menstruasi di butuhkan untuk mempersiapkan diri dalam menghadapi menarche terutama pada remaja putri. (Hastuti, 2014).

Ketidaksiapan dalam menghadapi menarche dapat berdampak buruk. Remaja putri yang tidak siap akan memiliki prilaku yang tidak baik dalam perawatan vulva hygienenya. Dengan hal itu maka akan membuat daerah sekitar kewanitaanya akan mudah sensitive, iritasi dan akan membuat wanita tidak percaya diri dan tidak nyaman dalam melakukan aktivitassehari-hari. (Lutfiya, 2016). Data dunia sebesar 76,3\% dari penduduk remaja didunia menyatakan bahwa populasi remaja putri sebagian besar mengalami stress saat menarche Data lain menunjukan sebanyak 54\% remaja putri mengalami rasa cemas saat menarche tidak bisa melakukan aktivitas seperti biasanya dengan teman sebaya (WHO, 2011). Hasil RISKESDAS Indonesia tahun 2012 menunjukan bahwa rata-rata usia menarche di Indonesia adalah 13 tahun, dengan kejadian lebih awal pada usia kurang dari 9 tahun atau lebih lambat sampai usia 17 tahun. Menarche lebih banyak di alami wanita pada umur 10-15 tahun. Menarche yang terlalu dini atau terlambat, bisa berakibat pada keadaan psikis remaja tersebut. Remaja yang akan mengalami menarche membutuhkan kesiapan mental yang baik. Kesiapan menghadapi menarche adalah keadaan yang menunjukan bahwa seseorang siap untuk mencapai salah satu kematangan fisik yaitu datangnya menarche. Remaja yang belum siap 77 | Edukasi Masyarakat Sehat Sejahtera (EMaSS) : Jurnal Pengabdian kepada Masyarakat Volume 2 No.1 Tahun 2020 
menghadapi menarche akan timbul keinginan untuk menolak proses fisiologis tersebut, mereka akan merasa haid sebagai sesuatu yang kejam dan mengancam, keadaan ini dapat berlanjut ke arah yang lebih negatif (Jayanti,dkk,2011). Tetapi berbeda bagi mereka yang telah siap dalam menghadapi menarche, mereka akan merasa senang dan bangga, dikarenakan mereka menganggap dirinya sudah dewasa secara biologis (Yanti,dkk, 2014).

Berdasarkan data dari Dinas Kesehatan Kabupaten Pangandaran jumlah remaja di Kabupaten Pangandaran khususnya yang berada di Kecamatan Cimerak sebanyak 1921 Jiwa. Jumlah remaja Usia 1014 tahun dengan jenis kelamin laki-laki berjumlah 995 jiwa dan jenis kelamin perempuan berjumlah 926 jiwa. Di Desa Sindangsasri populasi jumlah remaja usia 10-14 tahun terbanyak ke dua di wilayah kecamatan cimerak, sebanyak 549 Jiwa. Di SDN 1 Sindangsari Total remaja kelas V-VI yang belum mengalami Menarche berjumlah 30 orang.

\section{METODE}

Metode pengambilan kasus yang digunakan adalah studi deskriptif. Menurut Hidayat (2010) Metode deskriptif merupakan metode yang digunakan untuk menemukan pengetahuan yang seluas-luasnya terhadap objek pada suatu masa tertentu. Pengkajian kasus ini dilakukan di SDN 1 Sindangsari Desa Sindangsari Kecamatan Cimerak Kabupaten Pangandaran. Waktu untuk memberikan pendidikan kesehatan remaja putri tentang menarche ini di laksanakan 2 kali pertemuan mulai dari 15 Februari sampai 22 Februari 2020 dengan subjek yang terlibat dalam pemberian pendidikan kesehatan remaja putri tentang menarche ini adalah remaja putri SDN 1 Sindangsari kelas IV-VI berjumlah 30 orang yang belum mengalami menarche. Proses pengumpulan data menggunakan kuesioner kepada remaja putri untuk mengevaluasi pengetahuan remaja setelah dilaksanakannya kegiatan pemberian materi pendidikan kesehatan. Sedangkan Instrumen pengumpulan data dalam kegiatan pendidikan kesehatan ini terdiri dari: SAP, Leaflet dan kuesioner untuk mengukur pengetahuan remaja putri tentang Menarche yang berjumlah 20 soal dengan jenis jawaban pilihan ganda.

78 | Edukasi Masyarakat Sehat Sejahtera (EMaSS) : Jurnal Pengabdian kepada Masyarakat Volume 2 No.1 Tahun 2020 


\section{HASIL DAN PEMBAHASAN}

Sebelum dilakukan pendidikan kesehatan dilakukan terlebih dahulu pengkajian pengetahuan remaja putri tentang Menarche dengan melakukan pengisian Pre - Test. Setelah dilaksanakan kegiatan pendidikan kesehatan pada remaja putri tentang Menarche maka diperoleh hasil sebagai berikut:

Tabel 1. Distribusi Frekuensi Pengetahuan Remaja Mengenai Menarche

\begin{tabular}{ccccc}
\hline \multirow{2}{*}{ Pengetahuan } & \multicolumn{2}{c}{ Sebelum Pendidikan } & \multicolumn{2}{c}{ Sesudah Pendidikan } \\
\cline { 2 - 5 } & Frekuensi & Presentase & Frekuensi & Presentase \\
\hline Baik & 0 & 0 & 16 & $53,30 \%$ \\
Cukup & 17 & $56,70 \%$ & 14 & $46,70 \%$ \\
Kurang & 13 & $43,30 \%$ & 0 & 0 \\
\hline Rata-Rata & \multicolumn{2}{c}{$56,80 \%$} & & $78,10 \%$ \\
\hline
\end{tabular}

Berdasarkan Tabel 1 diatas dapat diketahui pengetahuan remaja putri di SDN 1 Sindangsari tentang Menarche sebelum dilaksanakan pendidikan kesehatan sebagian besar mempunyai pengetahuan cukup (56,7 \%). Sesudah dilaksanakan pendidikan kesehatan sebagian besar mempunyai pengetahuan baik $(53,3$ $\%)$. Dapat di ketahui rata-rata nilai sebelum dilakukan pendidikan kesehatan $(56,8 \%)$. dan sesudah dilakukan pendidikan kesehatan $(78,1 \%)$. terjadi kenaikan $(21,3 \%)$.

Tindak lanjut yang penulisan berikan kepada responden adalah memberikan pemahaman tentang tanda/gejala menarche seperti emosi meningkat dan perasaan sensitif, nyeri dan bengkak pada payudara, keputihan, gelisah/susah tidur, tubuh tidak fit, perut terasa mulas dan mual. Selain itu penulis memberikan saran untuk menghindari makanan yang asam atau pedas karena dapat mempengaruhi kelancaraan saat menstruasi dan perbanyak minum air putih.

Tindak lanjut selanjutnya penulis memberikan pemahaman mengenai Menstrual Hygiene kepada setiap responden salah satunya dengan menggunakan celana dalam yang tidak ketat dan berbahan katun yang mudah menyerap keringat. Menggunakan pembalut yang dapat menyerap darah haid, aman, nyaman dan lembut. Mengganti pembalut setiap 4 jam sekali/minimal 4-5 kali sehari.

Salah satu akibat kurangnya pemahaman Menstrual Hygiene adalah terjadinya gangguan kesehatan reproduksi seperti keputihan, infeksi saluran kemih (ISK), penyakit radang panggul (PRP) dan kemungkinan terjadi kanker leher rahim, sehingga dibutuhkan informasi yang sangat baik mengenai kesehatan reproduksi agar remaja memiliki pemahaman yang baik dan dapat mencegah ancaman penyakit reproduksi (Wakhidah, 2014).

79 | Edukasi Masyarakat Sehat Sejahtera (EMaSS) : Jurnal Pengabdian kepada Masyarakat Volume 2 No.1 Tahun 2020 
Berdasarkan hasil pengisian pretest dan posttest terdapat peningkatan pengetahuan remaja dari sebelum dilaksanakannya pendidikan kesehatan sampai sesudahnya dilaksanakan. Sebelum dilaksanakan pendidikan kesehatan sebagian besar mempunyai pengetahuan cukup $(56,7 \%)$. Sesudah dilaksanakan pendidikan kesehatan sebagian besar mempunyai pengetahuan baik (53,3\%). Usia sasaran berkisar antara 10-12 tahun dimana usia itu termasuk kategori remaja usia dini. Semakin bertambahnya usia seseorang akan semakin bijaksana sehingga menambah pengetahuannya. Dengan begitu remaja usia dini akan semakin siap saat mengalami Menarche (haid pertama).

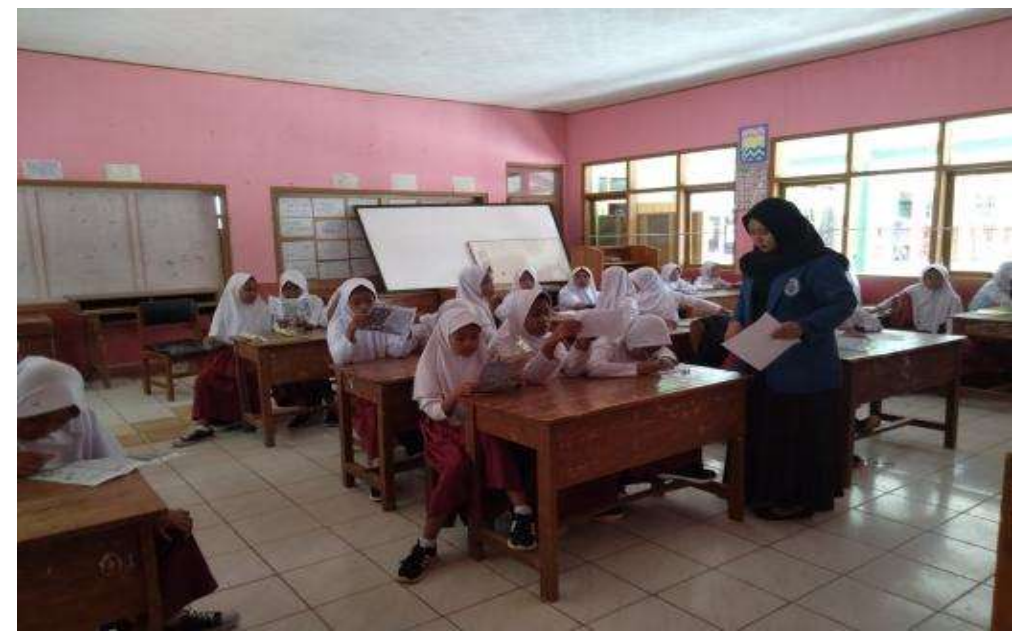

Gambar 1. Pendidikan Kesehatan pada Remaja Puteri

Sesudah dilaksankan pendidikan kesehatan pada remaja, dapat dilihat bahwa terjadi peningkatan pengetahuan $(21,3 \%)$. Hal ini menunjukan pendidikan kesehatan menjadi penyebab meningkatnya pengetahuan dan sikap remaja usia dini tentang Menarche di SDN 1 Sindangsari.

Menurut Notoatmodjo (2012) faktor yang mempengaruhi peningkatan pengetahuan seseorang adalah informasi dan pengalaman. Seseorang yang memiliki keluasan informasi, akan semakin memiliki pengetahuan yang lebih luas. Pengalaman berkaitan dengan umur dan pendidikan individu, pendidikan yang tinggi pengalamannya akan luas sedangkan umur semakin banyak maka pengalaman juga semakin banyak. Sehingga setelah diberikan informasi melalui penyuluhan, pengetahuan dan sikap semaja terjadi peningkatan. Seiring bertambahnya usia, remaja akan lebih berpengalaman dalam menstrual hygiene setelah diberikannya informasi yang benar.

Menurut Notoatmodjo (2010) Pengetahuan adalah hasil dari tahu setelah melakukan penginderaan terhadap suatu objek tertentu. Seseorang yang memiliki pengetahuan tinggi, maka ia akan mampu berfikir kritis. Seseorang yang memiliki pengetahuan tinggi tidak menjamin akan memiliki sikap dan perilaku yang 
positif. Karena dalam menentukan sikap selain ditentukan oleh pengethuan juka diperoleh oleh pikiran, keyakinan dan emosi yang memegang peran penting (Notoatmodjo, 2010).

\section{SIMPULAN}

Kegiatan ini berhasil meningkatkan pengetahuan remaja secara signifikan, hal ini juga dipengaruhi oleh penyuluh, ketertiban dan rasa ingin tahu sasaran dan proses pelaksanaan. Pendidikan kesehatan ini juga diharapkan bukan hanya berpengaruh pada peningkatan pengetahuan remaja saja, tetapi mampu merubah perilaku dan menjadikan perilaku bertanggungjawab pada kesehatan reproduksinya. Diharapkan kedepannya akan terus dilakukan kegiatan serupa khususnya untuk remaja dengan media dan pendekatan yang berbeda sehingga bukan hanya pengetahuannya saja yang meningkat tetapi perubahan perilakunya juga dapat diawasi secara berkesinambungan guna meningkatkan kesiapan mental/psikis remaja dalam menghadapi menarche.

\section{DAFTAR PUSTAKA}

Kemenkes. (2015). Situasi Kesehatan Reproduksi Remaja. http://www.depkes.go.id Kementrian Kesehatan Republik Indonesia. (2015).Profil Kesehatan Indonesia.

Lutfiya, I. (2016). Analisis kesiapan siswi sekolah dasardalam menghadapi Menarche. Biometrika dan Kependudukan. 135-145. Diakses pada 7 Maret 2018.

Mansur, H \& Budiarti, T. (2014). Psikologi Ibu dan Anak Untuk Kebidanan. Jakarta: Salemba

Manuaba, dkk. (2009). Memahami Kesehatan Reproduksi Wanita Edisi 2.Jakarta: EGC.

Marmi. (2014).Kesehatan Reproduksi. Yogyakarta : Pustaka pelajar

Miswanto. (2014). Pentingnya pendidikan kesehatan Reproduksi dan seksualitas pada Remaja. Jurnal studi Pemuda Vol.3, No 2, September 2014

Notoatmodjo, S. (2010). Metodologi penelitian Kesehatan. Jakarta : Rineka Cipta.

Notoatmodjo.(2012).Pendidikan Kesehatan.Jakarta:Rineka Cipta:2010.

Nursalam. (2011). Proses Dan Dokumentasi Keperawatan, Konsep Dan Praktek.Jakarta: Salemba medika Nurul Chomaria.(2018).Kenaliasa Remaja Anak.Solo: Tiga Serangkai

Proverawati . (2009). Menarche Menstruasi Pertama Penuh Makna. Yogyakarta:Nuha Medika

Respati.(2011). Problematika Remaja Akibat Kurangnya informasi Kesehatan Reproduksi. Fakultas Psikologi Universitas Esa unggal Jakarta

Sarwono. (2011). Psikologi Remaja Edisi Revisi. Jakarta: Rajawali pers.

Setiyaningrum E, Zulfa.(2014). Pelayanan Keluarga Berencana Dan Kesehatan Reproduksi. Jakarta: CV. Trans info media

Sugiyono. (2013). Metode Penelitian Pendidikan Pendekatan Kuantitatif, Kualitatif, Dan R\&D. Bandung: Alfabeta

81 Edukasi Masyarakat Sehat Sejahtera (EMaSS) : Jurnal Pengabdian kepada Masyarakat Volume 2 No.1 Tahun 2020 